\title{
珠江口盆地白云凹陷下地壳伸展与陆架 坡折的关系
}

\author{
张云帆 ${ }^{(1)}$, 孙珍 ${ }^{(1)}$ ，庞雄 ${ }^{(2)}$ \\ (1) 中国科学院边缘海地质重点实验室, 中国科学院南海海洋研究所, 广州 510301; \\ (2) 中国海洋石油有限公司深圳分公司技术部, 广州 510240 \\ * 联系人, E-mail: zhensun@scsio.ac.cn
}

收稿日期: 2012-12-20; 接受日期: 2013-07-01; 网络版发表日期: 2014-01-26

国家科技重大专项基金项目(编号：2011ZX05025-003-005)、国家重点基础研究发展计划(编号：2009CBZ19401)和国家自然科学基金青年 科学基金项目(批准号: 41206040)资助

\begin{abstract}
摘要随着深水油气勘探和深水盆地研究的推进, 白云凹陷陆架坡折在张裂结束后发生快速 跃迁、上下地壳伸展存在不均一性等一系列地质现象逐渐受到学者的关注, 这些问题的解决对被 动大陆边缘演化过程的认识具有重要的推动作用。根据中国海洋石油总公司(CNOOC)提供的地 震地球物理数据，计算出白云凹陷地壳的拉张因子 $(\beta)$ 分布. 并选取白云凹陷内 13 条精确解释的 长地震剖面, 分别计算出沿剖面的上下地壳拉张因子, 并获得拉张因子的平面分布, 揭示上下地 壳在拉张过程中的不同贡献. 结果显示: 白云凹陷全地壳拉张因子由西北向东南逐渐变大, 反映 了地壳由陆向洋减薄的特征。上地壳拉张因子较小, 而下地壳比上地壳的拉张贡献大, 表明白云 凹陷新生代变形受脆性伸展作用控制不大，而主要受韧性伸展作用控制。数值模拟计算过程表明 白云凹陷初始地壳应为热减薄地壳。下地壳拉张因子由北部向深海盆边缘逐渐增大，并出现两个 拉张中心, 分别对应于白云凹陷和荔湾凹陷。在 23.8 和 $13.8 \mathrm{Ma}$ 这两个时期, 陆架坡折形态都与 下地壳拉张因子等值圈闭的外缘走向近似，且都处于下地壳强烈变化的地区，推测由下地壳伸展 和下地壳流动引起的盆地沉积沉降作用是控制陆架坡折发育位置的一个重要因素.
\end{abstract}

关键词

白云凹陷

陆架坡折

拉张因子

下地壳
随着近年来油气资源的需求量日益增多，陆架 区的浅海油气储量已经不能满足国民经济需求，勘 探逐渐向洋陆过渡带深入. 南海北部珠江口盆地由 于富含油气资源, 并包含有岩石圈演化的丰富信息, 成为研究张裂大陆边缘和深水油气勘探的热点地区. 随着近 20 年来的研究, 对珠江口盆地的断裂系统、 沉积地层、地球化学、油气系统、等方面有了长足的
认识(龚再升等, 1997), 同时也浮现出一系列地质问 题: 珠江口盆地地壳伸展存在不均一性、陆坡在张裂 样式上明显不同于陆架地区、陆架坡折在张裂结束后 发生快速跃迁等. 上述地质问题是独立存在? 还是 在深部存在某种联系? 有待于我们深入研究.

陆架坡折是位于陆架和陆坡之间的过渡地带, 是陆架和陆坡两大地貌单元的自然分界. 该过渡带

中文引用格式: 张云帆, 孙珍, 庞雄. 2014. 珠江口盆地白云凹陷下地壳伸展与陆架坡折的关系. 中国科学: 地球科学, 44: 488-496

英文引用格式: Zhang Y F, Sun Z, Pang X. 2014. The relationship between extension of lower crust and displacement of the shelf break. Science China: Earth Sciences, 57: 550-557, doi: 10.1007/s11430-013-4676-4 
最突出的特征是地形坡度发生明显转折. 陆架坡折 的发育是受盆地沉降速率和沉积物供给速率共同控 制. 国内外学者的研究均显示珠江口盆地存在自陆 向洋的裂后异常加速沉降(Westaway 等, 1994; Clift 等, 2002; 廖杰等, 2001; 赵中贤等, 2010), Westaway 等 (1994) 将其解释为南海北部下地壳向华南大陆流动 所导致, Clift 等(2002)认为是由向洋方向低黏度的下 地壳过度伸展造成的. 本文基于前人提出的理论, 分 别计算白云凹陷的全地壳、上地壳、下地壳拉张因子, 揭示了南海北部陆坡区由表层到深层, 由陆向洋地壳 结构的变化趋势, 以及陆架坡折跃迁与深部结构的关 系, 这些问题的解决对认识被动大陆边缘演化过程以 及油气勘探资源潜力评价具有重要的推动作用.

\section{1 地质概况}

珠汇口盆地位于南海北部陆坡区(图 1), 是华南 大陆的水下延伸部分, 盆地构造具有南北分带和东 西分块的特点, 自北向南呈 NEE 向隆坳相间格局(龚 再升等, 1997; 陈长民等, 2003). 南海北部地壳厚度 由陆向洋逐渐减薄, Moho 面深度逐渐抬升(丘学林等, 2003; Zhang 等, 2008), 地壳厚度最薄处仅 $7 \mathrm{~km}$ (庞雄 等, 2007a; 黄春菊等, 2005), 盆地东部发育下地壳高 速层 (Qiu 等, 2001; 吴振利等, 2011). 白云凹陷位于

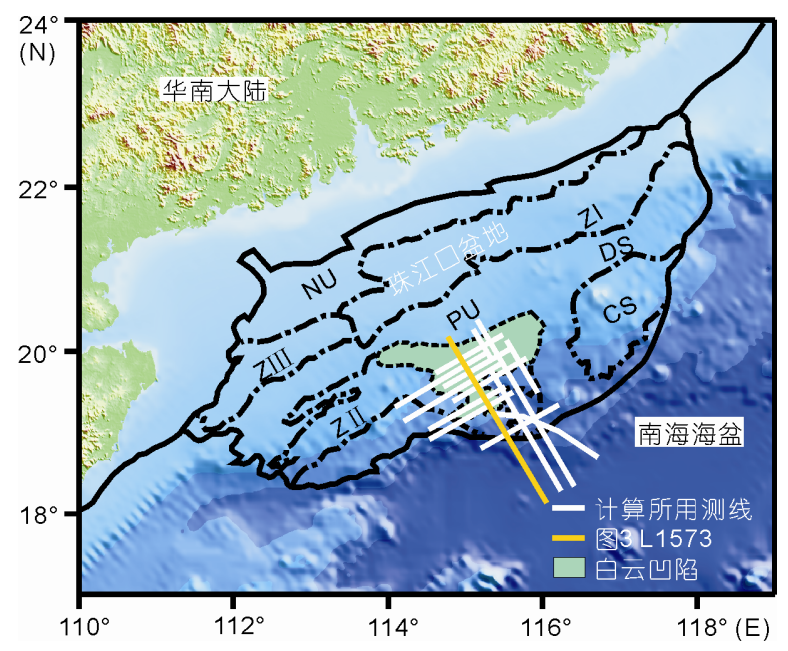

图 1 白云凹陷与测线位置图

NU. 北部隆起带; ZIII. 珠三凹陷; Z I . 珠一凹陷； Z II. 珠二凹陷; PU. 番禺低隆起; DS. 东沙隆起; CS. 潮汕凹陷
珠江口盆地南部的珠二坳陷内, 整体走向 NEE, 面积 大于 $20000 \mathrm{~km}^{2}$, 凹陷跨越大陆架边缘与斜坡的过渡 带, 直至深海区, 是南海北部陆缘最大的一个深水陆 坡沉积区(陈长民等, 2003).

珠江口盆地白云凹陷的陆架坡折曾发生过快速 的迁移(庞雄等, 2007a; 柳保军等, 2011). 在 $23.8 \mathrm{Ma}$ 之前，陆架坡折位于白云凹陷与荔湾凹陷之间的低隆 起上, 随着南海扩张脊向南跃迁, 使得 $23.8 \mathrm{Ma}$ 以来白 云凹陷产生强烈的沉降，陆架坡折突变式地跳跃到凹 陷的北侧，白云凹陷也由渐新世晚期的浅海陆架环境 转为陆坡深水环境; 至 $13.8 \mathrm{Ma}$ 坡折带跃迁至白云凹 陷的北部. 庞雄等(2007b)认为 $23.8 \mathrm{Ma}$ 所对应的渐新 统-中新统界面在珠江口盆地乃至南海都是一次大规 模的构造运动，并将该运动定名为“白云运动”.

\section{2 数据来源及方法}

本文所采用剖面来自中海石油深圳分公司 (CNOOC) 所采集长电缆剖面, 测线覆盖白云凹陷和 荔湾凹陷延伸至海盆边缘. 在被动陆缘张裂过程中, 岩石圈各层的伸展具有不均匀性, 从陆到海的伸展 也具有不均匀性. 地壳的拉张程度用拉张因子这一 参数来描述 $\left(\right.$ McKenzie, 1978), $\beta_{\mathrm{wc}}=t_{0} / t_{\mathrm{wc}} \cdot t_{0}$ 为初始 地壳厚度, 根据资料取 $32 \mathrm{~km}$ (Clift 等, 2002; 姚伯初 等, 2005 ; 王万银, 2007) ${ }^{1)}, t_{\mathrm{wc}}$ 为现今地壳厚度(图 2)(张云帆等, 2007).

计算上地壳拉张因子过程中, 首先要从剖面中 读出基底断裂参数, 代入公式进行计算, 以 L1573 剖 面为例(图 3, 位置见图 1), 从剖面上测量每个断层的 位置(以剖面一端为原点的 $X$ 轴坐标)、极性(正断层还

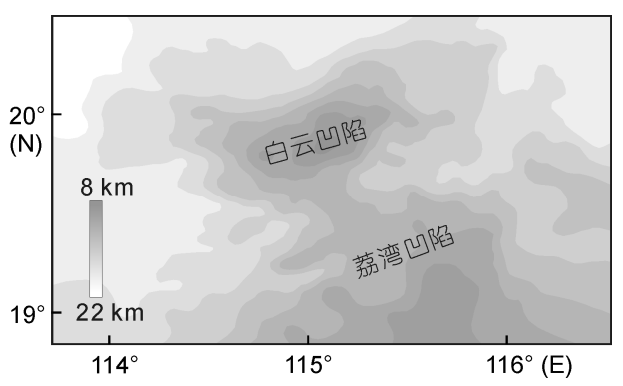

图 2 白云凹陷现今地壳厚度

1) 王万银. 2000. 中国近海及邻区重磁数据处理汇报. 西安建筑学院学术报告 




图 3 L1573 剖面结构图(胡登科, 2009)

是逆断层)、倾角和水平断距等, 运用以下公式(1) (3)(Davis 等, 2004; Kusznir 等, 1992), 得到上地壳拉 张因子 $\beta_{\mathrm{uc}}(\mathrm{uc}$ : upper crust)的分布.

$$
\begin{gathered}
\beta_{\mathrm{uc}}=1+\beta_{0} \cos ^{2}\left[\frac{\pi\left(x-x_{0}\right)}{w}\right], \\
E=\int\left[1-\frac{1}{\beta_{\mathrm{uc}}(x)}\right] \mathrm{d} x, \\
\beta_{\mathrm{uc}}(x)=\beta_{\mathrm{uc} 1}(x) \cdot \beta_{\mathrm{uc} 2}(x) \cdot \beta_{\mathrm{uc} 3}(x) \cdots \beta_{\mathrm{uc} n}(x) .
\end{gathered}
$$

其中 $E$ 为水平伸展量, $x$ 为水平位置, $w$ 为纯剪影响的
范围, $x_{0}$ 为断层位置坐标. 将所得的结果乘以误差系 数 $40 \%$ (Clift 等, 2002, 2006)得到一条测线的上地壳拉 张因子, 将 13 条测线的计算结果输入 sufur 软件, 运 用 Kriging 插值方法, 得到了全区上地壳拉张因子 $\beta_{\mathrm{uc}}$ (uc: upper crust)的分布.

在地壳的伸展变形过程中, 全地壳厚度始终为 上下地壳厚度之和. 因此, 根据现今全地壳厚度(图 2)、全地壳拉张因子(图 4)、上地壳拉张因子计算结 果(图 5), 假设初始全地壳厚度、上下地壳厚度比, 根 据以下公式即可以求出下地壳的拉张因子 $\beta_{\mathrm{lc}}$ (lc: lower crust $)$ 的分布: $\beta_{\mathrm{lc}}=t_{\mathrm{lc}} /\left(t_{\mathrm{wc}} / \beta_{\mathrm{wc}}-t_{\mathrm{uc}} / \beta_{\mathrm{uc}}\right)$. 式 中 $t_{\mathrm{lc}}$ 为初始下地壳厚度, $t_{\mathrm{wc}}$ 为初始全地壳厚度, $t_{\mathrm{uc}}$ 为 初始上地壳厚度, $\beta_{\mathrm{wc}}$ 为全地壳拉张因子, $\beta_{\mathrm{lc}}$ 和 $\beta_{\mathrm{uc}}$ 分 别为下地壳拉张因子与上地壳拉张因子.

\section{3 珠江口盆地白云凹陷的区域地壳拉张} 特征

此前笔者对南海北部的拉张因子进行计算，认 为珠江口盆地的拉张因子由北向南增大, 反映了由 陆向洋拉张程度逐渐增大. Kusznir(1992)对白云凹陷 一条剖面地壳伸展的数值模拟结果得到拉张因子达

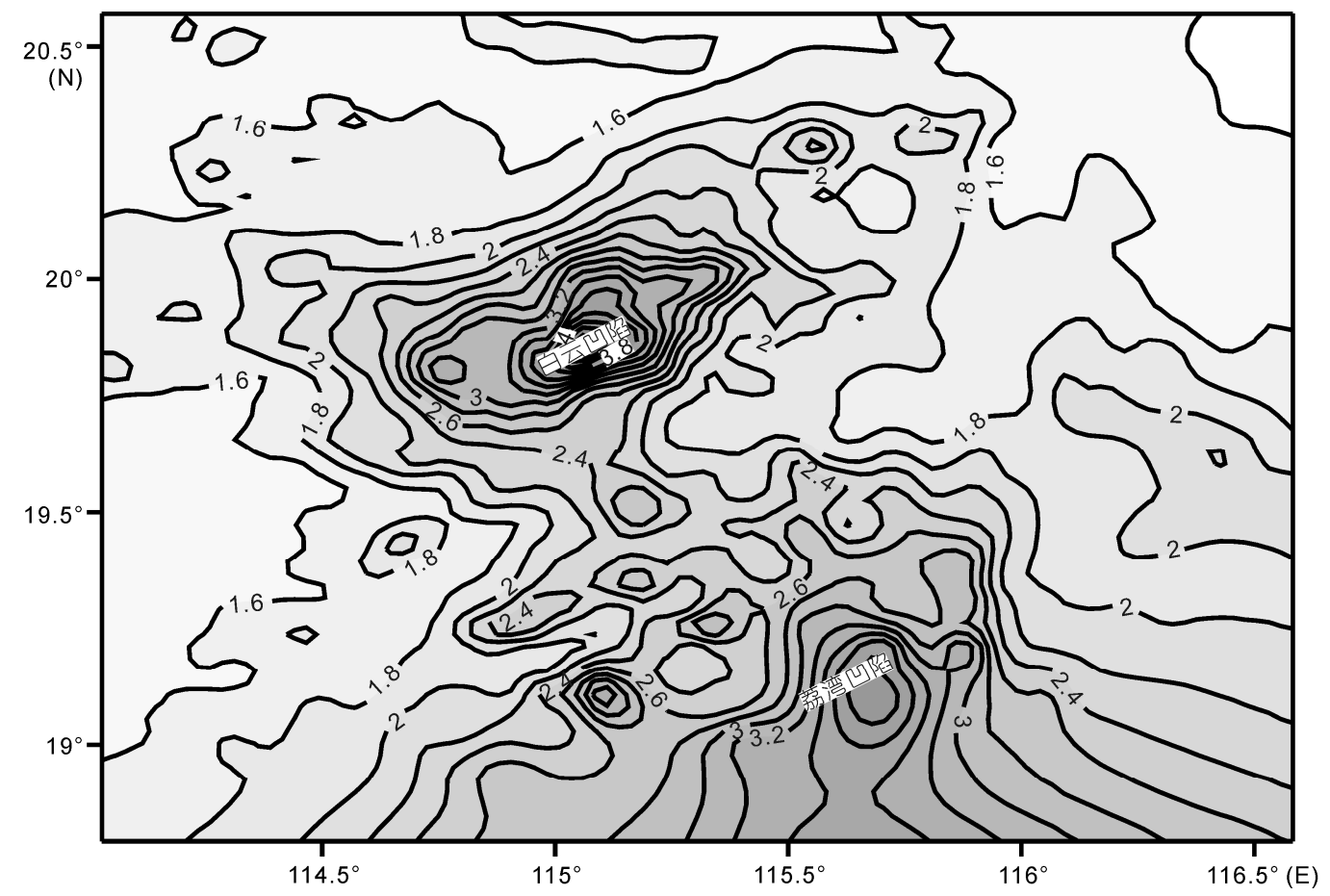

图 4 白云凹陷地壳拉张因子等值线图(张云帆等, 2007) 
到 4(Davis 等, 2004). 本文利用新数据对白云凹陷区 域地壳拉张因子进一步计算时, 发现全地壳存在两 个拉张中心(图 4), 分别为白云凹陷和荔湾凹陷的南 缘, 最大值都达到 4 , 与前人的模拟结果相符, 白云 凹陷北部的拉张因子逐渐减小到 2 以下, 中部的白云 隆起拉张因子在 2.2 左右, 而南部荔湾凹陷向南连接 南海海盆, 拉张因子平均在 $2.5 \sim 3$, 向海盆方向增大. 白云凹陷整体全地壳拉张因子较大, 表明白云凹陷 经历较强烈的拉张作用.

Davis 等( 2004)通过研究包括珠江口盆地在内的 世界范围内多处的实例地壳剖面以及数值模拟, 在 McKenzie 的理论基础上提出了被动大陆边缘伸展作 用随深度发生变化的模式. 如他们对珠江口盆地 OBS93 测线的计算、Clift 等 $(2002,2006)$ 通过对珠江 口盆地 1554 测线的计算, 还有更多来自全世界范围 内的被动陆缘研究(Roberts 等, 1997; Karner 等, 2003; Driscoll 等, 1996), 都一致地揭示出在被动陆缘张裂 过程中, 岩石圈各层的伸展具有不均匀性, 从陆到海 的伸展也具有不均匀性. 因此本文探索拉伸过程中 上地壳与下地壳的在伸展状态下的不同贡献. 本文 划分上下地壳的依据与地球物理按照速度结构所划 分的不同, 本文认为上地壳的拉张与脆性断裂造成 的伸展有关, 而发生韧性伸展的为下地壳. 前者的大 小主要控制盆地断陷期的沉降量, 后者则主要影响 盆地的热流异常和热衰减沉降的大小. 上地壳拉张 因子 $\beta_{\mathrm{uc}}$ 分布的几何形态由断层参数决定, 而下地壳 $\beta_{\mathrm{lc}}$ 的分布形态则由下地壳厚度变化规律决定.

\section{4 珠江口盆地白云凹陷上地壳拉张因子分 布特征}

研究区的上地壳拉张因子分布存在两个拉张中 心(图 5), 其中一个位于白云凹陷, 由一条 NW 向和 三条 NE 向测线的交点形成上地壳拉张因子的峰值带, 最大值圈闭为 1.8 , 个别点达到 2 左右, 向 $\mathrm{SW}$ 和 $\mathrm{NE}$ 两侧逐渐减小. 曲线的整体走向为 NW 向, 而白云凹 陷走向为 $\mathrm{NE}$ 向, 这种差异虽不能排除测线密度不够 所带来的影响，造成沿测线等值线局部圈闭集中，但 也有这样的可能: NE 和 NW 向断裂体系所造成的上 地壳伸展与白云凹陷的整体沉降并不一致. 另一个 拉张中心位于荔湾凹陷, 靠近洋陆过渡带的位置. 最 大值由一个范围较小的狭长型圈闭组成, 上地壳拉
张因子大于 1.9 , 也有个别点达到了 2 以上. 等值线 圈闭向 NW 和 SE 两边逐渐减小, 分布形态为 NE 向, 与荔湾凹陷的展布大体一致. 在白云凹陷的西南侧, 有一个次级的圈闭, 大致对应着西南断阶带. 由上地 壳拉张因子等值线分布及其与沉积中心的对应关系 可以看出, 上地壳拉张减薄区基本上控制了凹陷的 沉积范围, 但并非沉积过程的决定因素.

\section{5 珠江口盆地白云凹陷下地壳拉张因子分 布特征}

根据以上公式计算剖面下地壳拉张因子时, 设 上地壳在拉张前的初始厚度为不同值时, 得到的下 地壳拉张因子不同. 笔者此前对白云凹陷内长电缆 剖面进行下地壳拉张因子的计算, 发现白云凹陷张 裂前为减薄的地壳(图 6), 初始地壳厚度介于 $25 \sim 18$ $\mathrm{km}$ (张云帆, 2007), 因此我们考虑了以下三种情况, 分别取 25, 18 和介于二者之间的 $22 \mathrm{~km}$ 为初始地壳厚 度. Yao 等(1998)关于南海北部陆缘结构剖面的探测, 认为汕头-香港断裂带地区上地壳为 $6.7 \mathrm{~km}$, 下地壳 厚度为 $19.3 \mathrm{~km}$, 上下地壳厚度比约为 $1: 3$, 而广东大 陆至沿海的地壳结构可看作是未被明显拉伸的地壳 初始状态, 因此本文认为白云凹陷初始地壳应为 “脆 韧地壳厚度比”小的减薄地壳(图 6), 取上下地壳厚度 比 $1: 3$. 因此本文计算了以下三种情况.

（1）当全地壳为 $22 \mathrm{~km}$, 上下地壳厚度比 $1: 3$ 时 (图 7), 白云凹陷下地壳拉张因子分布图揭示了两个 拉张中心, 一个是白云凹陷, 拉张因子平均在 2 左右, 凹陷中心个别数据点达到 3.5 , 向四周减小; 第二个 拉张中心为荔湾凹陷, 下地壳拉张因子最大值达到 3 以上, 向北减小, 向南逐渐进入南海深海盆, 下地壳 拉张因子达到 3. 等值线的分布形态虽受测线位置控 制, 但与白云凹陷的形态吻合, 有从北向南逐渐增大 的趋势. 从整体上看, 白云凹陷 $\beta_{\mathrm{lc}}$ 在最北部的约为 1 向南增加到 3 以上, 在 $23.8 \mathrm{Ma}$ 之前至 $13.8 \mathrm{Ma}$ 这两 期坡折带的位置都与下地壳拉张因子等值线走向近 似, 且位于下地壳强烈变化的位置. 坡折带南北两侧 的下地壳拉张因子由 3.5 递减至 1, 下地壳拉张因子 变化强烈.

（2）当初始全地壳为 $25 \mathrm{~km}$, 上下地壳厚度比 $1: 3$ 时(图 8), 下地壳拉张因子在白云凹陷和荔湾凹 




图 5 珠江口盆地白云凹陷上地壳拉张因子等值线图

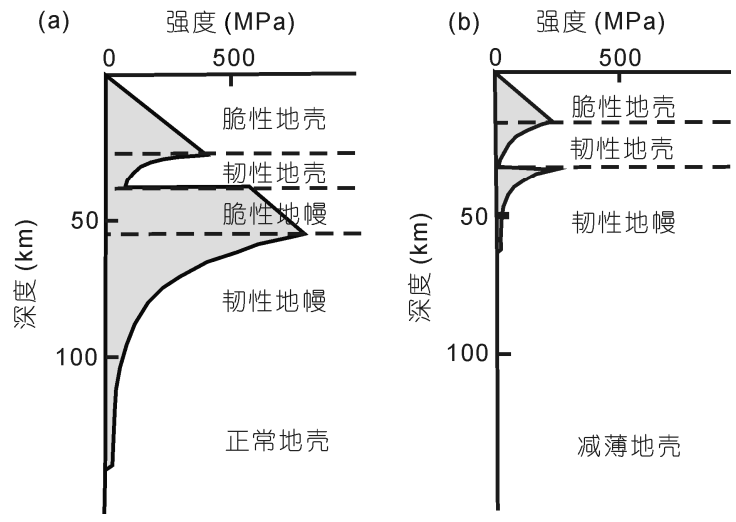

图 6 岩石圈流变结构图(Brun, 1999)

陷发生强烈拉张, 等值线圈闭最大达到了 3.5 , 个别 值达到 4 以上，等值线形态与盆地走向一致，且与
23.8 和 $13.8 \mathrm{Ma}$ 两期陆架坡折走势一致, 总体上由陆 架至陆坡下地壳拉张因子逐渐增大.

（3）当初始全地壳为 $18 \mathrm{~km}$, 上下地壳厚度比 $1: 3$ 时 (图 9), 各测线的下地壳拉张因子 $\beta_{\mathrm{lc}}$ 平均在 $1 \sim 2.5$, 等值线走向与前两种情况相似. 从平面分布 看, 下地壳拉张因子最大等值线圈闭为 2.5 , 下地壳 拉张因子分别在白云凹陷与荔湾凹陷出现最大值, 向海盆方向增大. 23.8 和 $13.8 \mathrm{Ma}$ 两期陆架坡折位置 与等值线走势相似，且位于等值线强烈变化的区域.

综合下地壳拉张因子的三种情况，我们发现下 地壳拉张因子急剧变化带与古陆架坡折位置近似对 应, 下地壳伸展是陆架坡折迁移的重要因素. 在 23.8 $\mathrm{Ma}$ 之前, 陆架坡折位于白云凹陷与荔湾凹陷两个拉 张中心之间(图 7,8,9 中黄色线), 坡折带东西两侧的 


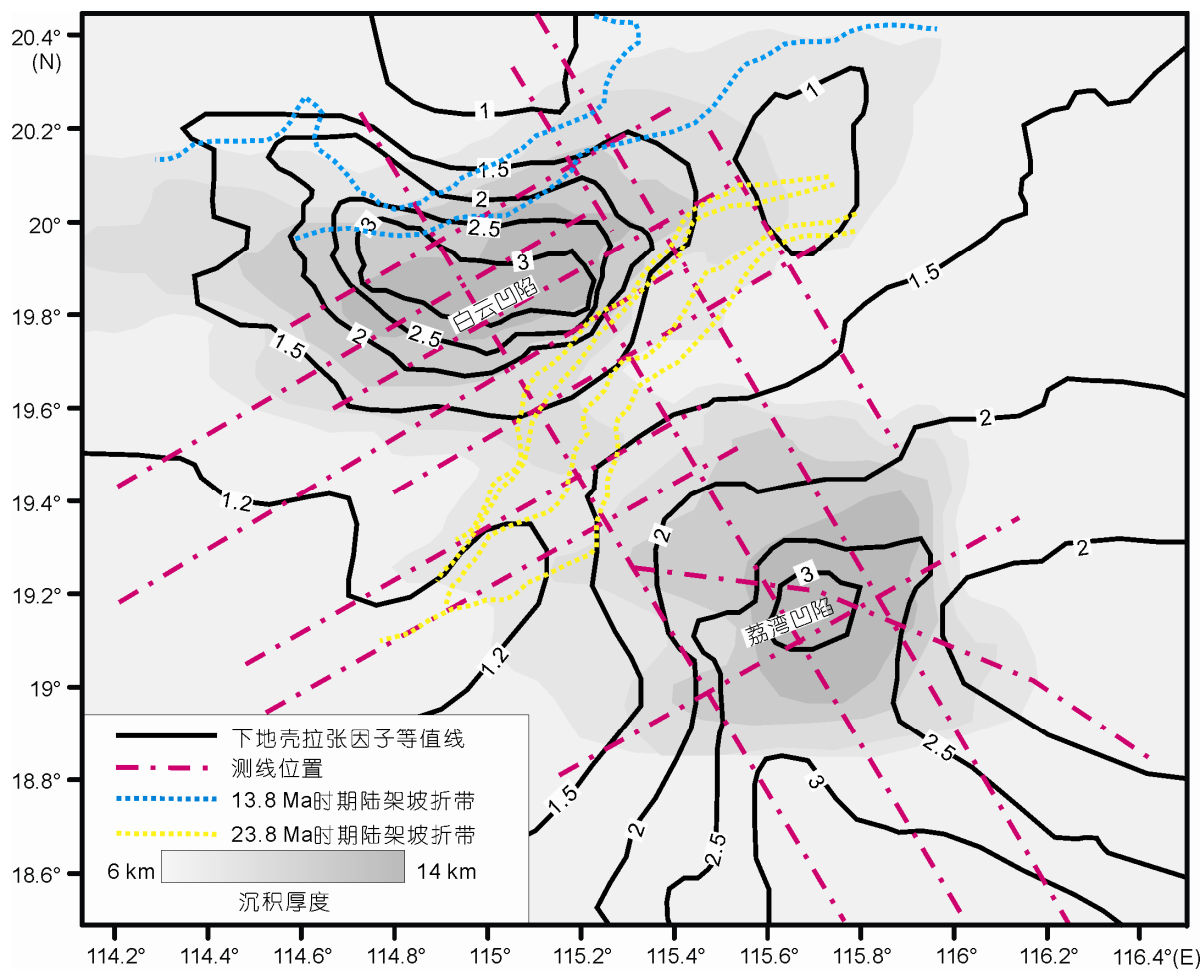

图 7 珠江口盆地白云凹陷下地壳拉张因子等值线分布图 假设初始全地壳厚度为 $22 \mathrm{~km}$, 上下地壳比为 $1: 3$



图 8 珠汇口盆地白云凹陷下地壳拉张因子等值线分布图 假设初始全地壳厚度为 $25 \mathrm{~km}$, 上下地壳比为 $1: 3$ 




图 9 珠江口盆地白云凹陷下地壳拉张因子等值线分布图

假设初始全地壳厚度为 $18 \mathrm{~km}$, 上下地壳比为 $1: 3$

下地壳拉张因子由 3.5 递减至 1(图 7). 该期坡折带控 制了低位体系域的发育和分布, 沉积了相对富砂低 位陆架边缘三角洲沉积体与陆坡深水扇砂体, 成为 深水区最有利的储层发育带(柳保军等, 2011). 23.8 $\mathrm{Ma}$ 之后, 白云凹陷发生强烈的沉降, 陆架坡折向白 云凹陷北坡退缩，控制了该层序高位域的沉积; 至 $13.8 \mathrm{Ma}$ 坡折带跃迁至白云凹陷的北部(图 7 9中蓝色 线), 坡折带南北两侧的下地壳拉张因子急剧递减. 这两个时期的陆架坡折形态都与等值线走向近似, 且都处于下地壳拉张因子强烈变化的地区, 推测由 下地壳伸展和下地壳流动引起的盆地沉降沉积幅度 的差异是陆架坡折出现位置迁移的控制重要因素.

\section{6 陆架坡折跃迁与深部活动的关系探讨}

结合白云凹陷上地壳和下地壳拉张因子的计算 结果, 我们不难看出, 下地壳在拉张过程中贡献大于 上地壳, 凹陷以㓞性伸展为主. 正如上面数值计算过 程所揭示的, 白云凹陷的初始流变结构应为减薄型
地壳，导致下地壳韧性伸展变形在总伸展量中占有 更高的比例，陆架坡折的迁移受下地壳韧性伸展和 流动的控制. 然而下地壳流动是需要条件的, 并且会 影响盆地的沉降过程, 进而影响陆架坡折的迁移. 低 黏度是下地壳流动的必要条件(Brun，1999), 其数量 级约为 $10^{19} \mathrm{~Pa} \cdot \mathrm{s}$ (McKenzie 等, 2002; Westaway, 1994, 2002), 而 Clift 等(2002)认为南中国大陆坡的下地壳 黏度为 $10^{18} \sim 10^{19} \mathrm{~Pa} \cdot \mathrm{s}$. Westaway(2002)也证明了下地 壳的有效黏度为 $1 \times 10^{19} \sim 4 \times 10^{20} \mathrm{~Pa} \cdot \mathrm{s}$. 强度弱、黏度 低的下地壳可以在地壳厚度变化产生的压力驱动下, 发生横向流动, 由地壳较厚处流向减薄处, 如青藏高 原中下地壳的向东流动，以及在裂谷区的下地壳流 动, Morley 等(2006)等用这一机制来解释一些超深的 沉积盆地. Huismans 等 (2011)在总结岩石圈伸展随 深度变化的两个端元时提出, 当下地壳为强度低的 粘性层时, 下地壳的存在减慢了上部脆性地壳的变 形，从而使岩石圈地幔早于地壳发生破裂. 在裂后期 当沉积速率很大时, 由于深部对地表过程即沉积物 的加载的响应，下地壳将发生从裂谷中心向外的侧 
向流动, 从而造成裂谷的进一步沉降. 凹陷长期持续 沉降使上地壳发生脆性断裂形成地堑或半地堑, 地 形坡度的迅速变化, 影响上覆水体运动和沉积物运 移, 形成陆架坡折. 因此, 在下地壳强烈减薄的地区 可能形成带具有独特的沉积沉降作用过程, 成为陆 源碎屑物质从陆架向陆坡和大洋搬运的沉积场所, 是陆架坡折迁移的重要因素.

\section{7 结论}

（1）珠江口盆地白云凹陷上地壳拉张因子从 1 增 大到 1.9. 向 $\mathrm{SW}$ 和 $\mathrm{NE}$ 两侧逐渐减小, $\mathrm{NW}$ 向断裂体 系所造成的上地壳伸展与白云凹陷的整体沉降并不 一致. 等值线走向与 23.8 和 $13.8 \mathrm{Ma}$ 两期陆架坡折位
置不相符，由上地壳拉张因子等值线分布及其与沉 积中心的对应关系可以看出，上地壳拉张减薄区基 本上控制了凹陷的沉积范围, 但并非沉积过程的主 要因素.

（2）在白云凹陷伸展过程中，下地壳比上地壳拉 张程度大, 表明白云凹陷受脆性减薄作用控制不大, 而主要受韧性伸展作用. 下地壳拉张因子由南海北 部向海盆边缘逐渐增大到 3 以上，等值线走势与白云 凹陷、荔湾凹陷的形态符合, 下地壳拉张因子等值线 圈闭与陆架坡折位置近似对应. 在 23.8 和 $13.8 \mathrm{Ma}$ 这 两个时期的陆架坡折形态都与等值线圈闭走向近似, 且都处于下地壳强烈变化的地区, 推测由下地壳伸 展和下地壳流动引起的盆地沉降沉积作用是陆架坡 折发生位置迁移的一个重要控制因素.

\section{参考文献}

陈长民, 施和生, 许仕策, 等. 2003. 珠江口盆地(东部)第三系油气藏形成条件. 北京: 科学出版社. 16-18

龚再升, 李思田, 谢泰俊, 等. 1997. 南海北部大陆边缘盆地分析与油气的聚集. 北京: 科学出版社. 24-25

胡登科. 2009. 南海北部陆坡至深海盆的地壳结构及其构造涵义. 硕士学位论文. 北京: 中国科学院研究生院. 36-40

黄春菊, 周蒂, 陈长民, 等. 2005. 深反射地震剖面所揭示的白云凹陷的深部地壳结构. 科学通报, 50: 1024-1031

柳保军, 庞雄, 颜承志. 2011. 珠江口盆地白云深水区渐新世-中新世陆架坡折演化及油气勘探意义. 石油学报, 32: 234-243

廖杰, 周蒂, 赵中贤, 等. 2011. 珠江口盆地白云凹陷裂后异常沉降的数值模拟. 中国科学：地球科学, 41: 504-517

庞雄, 陈长民, 彭大钧, 等. 2007a. 南海珠江深水扇系统及油气. 北京: 科学出版社. 150-200

庞雄, 陈长民, 邵否. 2007b. 白云运动: 南海北部渐新统-中新统重大地质事件及其意义. 地质评论, 53: 1-9

丘学林, 施小斌, 阎贫, 等. 2003. 南海北部地壳结构的深地震探测和研究新进展. 自然科学进展, 13: 231-236

吴振利, 李家彪, 阮爱国. 2011. 南海西北次海盆地壳结构: 海底广角地震实验结果. 中国科学: 地球科学, 41: 1463-1476

姚伯初, 万玲, 吴能友. 2005. 南海新生代构造演化及岩石圈三维结构特征. 地质通报, 24:1-8

张云帆, 孙珍, 周蒂, 等. 2007. 南海北部陆缘新生代地壳减薄特征及其动力学意义. 中国科学 D 辑: 地球科学, 37: 1-8

赵中贤, 周蒂, 廖杰, 等. 2010. 珠江口盆地陆架区岩石圈伸展模拟及裂后沉降分析. 地质学报, 84: 1135-1145

Brun J P. 1999. Narrow rifts versus wide rifts: Inferences for the mechanics of rifting from laboratory experiments. Philos Trans R Soc A—Math Phys Eng Sci, 357: 695-712

Clift P, Lin L, Barckhausen U. 2002. Evidence of low flexural rigidity and low viscosity lower continental crust during continental break-up in the South China Sea. Mar Petrol Geol, 19: 951-970

Clift P, Sun Z. 2006. The sedimentary and tectonic evolution of the Yinggehai-Song Hong basin and the southern Hainan margin, South China Sea: Implications for Tibetan uplift and monsoon intensification. J Geophys Res, 111: 1-28

Davis M, Kusznir N J. 2004. Depth-dependent lithospheric stretching at rifted continental margins. Proceedings of NSF Rifted Margins Theoretical Institute. Colnmbia: Columbia University Press. 92-137

Driscoll N, Karner G D. 1996. Tectonic and stratigraphic evolution of the Carnarvon Basin, northwest Australia. Miner Energy Res Inst Western Aust. 1-8

Huismans R, Beaumont C. 2011. Depth-dependent extension, two-stage breakup and cratonic underplating at rifted margins. Nature, 473: 74-78

Karner G D, Driscoll N W, Barker D H. 2003. Syn-rift regional subsidence across the West African continental margin: The role of lower plate ductile extension. Geol Soc London Spec Publ, 207: 105-111

Kusznir N J, Ziegler P A. 1992. The mechanics of continental extension and sedimentary basin formation-a simple-shear/pure-shear flexural cantilever model. Tectonics, 215: 117-131

McKenzie D P. 1978. Some remarks on the development of sedimentary basins. Earth Planet Sci Lett, 40: 25-32

McKenzie D P, Jackson J. 2002. Conditions for flow in the continental crust. Tectonics , 21: 1-7 
Morley C K, Westaway R. 2006. Subsidence in the super-deep Pattani and Malay basins of Southeast Asia: A coupled model incorporating lower crustal flow in response to post-rift sediment loading. Basin Res, 18: 51-84

Qiu X L, Ye S Y, Wu S M, et al. 2001. Crustal structure across the Xisha Trough, northwestern South China Sea. Tectonophysics, 341: 179-193

Roberts A M, Lundin E R, Kusznir N J. 1997. Subsidence of the Voring Basin and the influence of the Atlantic continental margin. J Geol Soc, 154: $551-557$

Westaway R. 1994. Re-evaluation of extension across the Pearl River Mouth Basin, South China Sea: Implication for continental lithosphere deformation mechanisms. J Struct Geol, 16: 823-838

Westaway R. 2002. Geomorphological consenquences of weak lower continental crust, and its significance for studies of uplift, landscape evolution, and the interpretation of river terrace sequences. Netherlands Geosci, 81: 283-303

Yao B C, Hayes D E. 1998. Lithospheric deformation under the effect of an extensional stress field. J Geol Soc China, 41: 517-534 